\title{
CARACTERIZACIÓN DE LA MUJER EN LA FÁBULA DE AVIANO DE NUTRICE ET INFANTI*
}

\author{
Francisca del Mar Plaza Picón \\ IEMYR. Universidad de La Laguna \\ fmplazap@ull.edu.es
}

\author{
In memoriam \\ Isabel García Gálvez
}

\section{RESUMEN}

Son muchos los ámbitos desde donde podemos acercarnos a la visión y consideración de la mujer desde la Antigüedad a la Edad Media (factores jurídicos, literarios, etc.). En este trabajo parto del análisis de la fábula I de Aviano para seguidamente atender tanto a las fuentes en las que se inspira el fabulista como a las versiones que posteriormente circularon de la misma, muchas de ellas con una clara intención misógina.

Palabras Clave: Fábula, Aviano, arquetipo, mujer.

\section{ABSTRACT}

"Characterization of the woman in Aviano's fable De nutrice et infanti». There are many perspectives from which we can approach the vision and consideration of women from Antiquity to the Middle Ages (legal, literary, etc.). In this work I start with the analysis of Aviano's fable I and then proceed to tackle the sources on which this fabulist drew. Additionally, I will also focus on the different versions that came out from the original text, many of them with a clear misogynist intention.

KEY WORDS: Fables, Avianus, archetype, women.

\section{INTRODUCCIÓN}

Las fábulas constituyen un instrumento de gran valor a la hora de examinar la consideración de la mujer en distintos contextos culturales e ideológicos y de valorar la influencia de la actitud claramente misógina de la tradición grecolatina. La capacidad didáctica, la finalidad moralizadora de la fábula y sus características formales propician el hecho de que este género se revele como una de las vías más adecuadas para el análisis de ciertos tópicos y estereotipos que sobre la mujer y su comportamiento se transmite en la Edad Media, época en la que la fábula goza de gran popularidad. Es por ello por lo que debe atenderse a su tipología, al lenguaje alegórico, 
al análisis de la simbología y al examen de los personajes que caracterizan al género femenino. Para el análisis de las características que se atribuyen a las mujeres parece, además, apropiada la noción de «arquetipo» en tanto que representación que se entiende como modélica ya que en las fábulas se ponen de manifiesto esquemas de comportamiento que forman parte del imaginario colectivo en cada momento. Es cierto que, aunque las mujeres griegas o romanas no constituyesen un grupo homogéneo, su consideración como grupo permitía dibujar rasgos comunes que conforman arquetipos, independientemente de otros factores como la categoría social. De hecho, estas características suelen formar parte del material del que se nutren máximas y apólogos, en general, de naturaleza misógina. En todo caso, a la hora de determinar qué se valora como misoginia en los textos, creo que es conveniente, máxime en el caso que nos ocupa, discernir si el «escritor está más interesado en ser chistoso que en satirizar a las mujeres en general» (Cortés Tovar, 2000: 15), o si el fabulista está reflejando otras cuestiones que posteriormente han sido objeto de interpretaciones misóginas.

El hecho de que una misma fábula haya sido adaptada o traducida desde la Antigüedad grecolatina hasta los siglos de la Ilustración y que de la misma existan versiones en griego, en latín o en vernáculo, tanto en prosa como en verso, esto es, su carácter hipertextual (Mañas, 1999: 226) permite y reclama un estudio pormenorizado de cómo cada autor en cada época ha transmitido su mensaje.

Resulta curioso que, frente a la visión crítica y generalmente misógina que se ofrece en apólogos y fábulas, Aviano no presente composiciones dedicadas a las mujeres y que la fábula I sea la única en la que ofrece un rasgo que se considera propio del género femenino ${ }^{1}$. Es por ello que, con objeto de estudiar sobre todo las distintas interpretaciones de que ha sido objeto esta composición a lo largo de los siglos, acometo el análisis de la fábula I de Aviano.

\section{AVIANO}

Aviano, autor de cuarenta y dos fábulas, que suele situarse en el siglo $\mathrm{V}$ d.C., conoció un gran éxito en la Edad Media, sus fábulas durante el siglo IX y siguientes junto con los Disticha Catonis formaban parte del programa escolar, hecho que explica la rica tradición manuscrita de este autor. Se hicieron versiones en prosa y, además,

* Trabajo enmarcado en el Proyecto de Investigación FFI2016-76165-P de ayudas a Proyectos de I+D correspondientes al Programa Estatal de Fomento de la Investigación Científica y Técnica de Excelencia, Subprograma Estatal de Generación de Conocimiento, Plan Estatal de Investigación Científica y Técnica y de Innovación 2013-2016.

${ }^{1}$ En el otro extremo se sitúa buena parte de las fábulas de Fedro cuyo carácter misógino ha sido objeto de diversos estudios como los de Nøjgaard (1967: 169-170), Cascón Dorado (1986), De Maria (1987). 
fueron la fuente de inspiración de los conocidos como Novi Avieni (Hervieux, 1894: 159-248). Precisamente por su valor moral los gramáticos medievales incluyeron estas fábulas entre las obras que debían leerse y fueron objeto de comentarios e imitaciones hasta los siglos XVI y XVII (Mañas Núñez, 1998: 280).

\section{DE NUTRICE ET INFANTI}

Esta fábula en la que un lobo se siente engañado por una nodriza deriva, como se verá más adelante, de una fábula de Babrio, quien pareció inspirarse, a su vez, en una fábula de Esopo. Aftonio presenta también una composición similar. Por ello analizaré de forma comparada dichas composiciones, comenzando por la fábula de Aviano cuyo texto reproduzco a continuación, siguiendo la edición realizada por Gaide (1980: 78-79).

Rustica deflentem paruum iuraverat olim ni taceat, rabido quod foret esca lupo.

Credulus hanc vocem lupus audiit, et manet ipsas pervigil ante fores, irrita vota gerens;

nam lassata puer nimiae dat membra quieti, spem quoque raptori sustulit, inde fames.

Hunc ubi siluarum repetentem lustra suarum ieiunum coniux sensit adesse lupa:

«Cur, inquit, nullam referens de more rapinam, languida consumptis sed trahis ora genis?»

«Ne mireris, ait, deceptum fraude maligna uix miserum uacua delituisse fuga.

Nam quae praeda, rogas, quae spes contingere posset, iurgia nutricis cum mihi verba darent?"

Haec sibi dicta putet seque hac sciat arte notari femineam quisquis credidit esse fidem.

El personaje que en Esopo es representado por una vieja, en Babrio por una nodriza-vieja, y en Aftonio por una nodriza, aquí es desempeñado por una campesina cuya edad desconocemos. Dicha campesina amenaza a un niño que llora sin cesar diciéndole que, si no se calla, servirá de alimento a un lobo furioso, todo ello expuesto en el primer dístico. A continuación, dedica dos dísticos a describir el comportamiento del confiado lobo que, tras aguardar en vano, pierde la esperanza, ya hambriento, cuando el niño se duerme. En los siguientes dos dísticos se detiene en narrar el regreso a su guarida, lugar en el que se halla su esposa, quien en estilo directo pregunta la causa de que no traiga ninguna presa y tenga tan mal aspecto. Ante esta pregunta que el poeta refleja en estilo directo, el lobo procede a explicar en dos dísticos que ha sido víctima de pérfido engaño y que sus males son la consecuencia de confiar en una nodriza.

En el relato se contrapone el comportamiento humano frente al animal. La nodriza-campesina, el niño, el lobo y la loba forman parte de esta historia en la que 
la acción se desarrolla sin que se establezca ningún contacto entre los seres humanos y los animales. De hecho, el ser humano es observado por parte del animal sin que se dé cuenta y es el animal el que procede a la valoración de su comportamiento. Es por ello por lo que, el último dístico (original o apócrifo) funciona como un auténtico epimitio en el que se da una particular interpretación de la narración, circunscrita a la mujer, como enseñanza o máxima moralizadora en la que se pone de manifiesto una característica que se le asigna al género femenino como propia, esto es, la consideración de que no es aconsejable fiarse de las mujeres.

No obstante, las palabras finales del lobo permitirían suponer que Aviano dejaría al propio lector que coligiese su propia interpretación. A este respecto, debe tenerse en cuenta que muchos de los epimitios de Aviano son apócrifos (Gaide, 1980: 33-36), aunque para Ellis este forma parte de aquellos cuya atribución a Aviano no presenta a duda (1887: XXXI). En cualquier caso, no resulta fácil encontrar la causa de que Aviano compusiese únicamente para un tercio de sus fábulas un epimitio de naturaleza moral en dísticos elegiacos, cuando en ocasiones pone fin a la fábula con una observación puesta en boca de uno de los personajes de la historia (Haskett, 1914: 12). La presencia de un dístico final de naturaleza moral debe ponerse en relación con el proceder de su fuente y, en el caso que nos ocupa, Babrio cierra su fábula, como se verá seguidamente, con las palabras del lobo a su compañera, al igual que Avianus cerraría sin este dístico, según Haskett (1914: 14). Sin embargo, Ellis considera que el epimitio de esta fábula es absolutamente necesario para completar el sentido. Pero si comparamos ambas composiciones, podría concluirse con Haskett (1914: 18) que Aviano pone fin a su fábula sin epimitio y que el sentido que muestra esta composición en Babrio concuerda perfectamente con la observación final del lobo en Aviano.

\section{ESOPO Y BABRIO}

Esta fábula se corresponde concretamente con la 16 de Babrio, si bien Aviano ha procedido a ampliar el texto. Asimismo, debe señalarse que Babrio se inspiraría en una fábula similar que presenta Esopo 158 (Hsr. 163, Ch. 223) en la que se cuenta que un lobo hambriento oyó a una anciana amenazar a un niño que estaba llorando con echarlo al lobo, si no se callaba. El lobo se quedó esperando y al llegar la noche escuchó nuevamente a la anciana diciéndole al niño que si llegaba el lobo, lo matarían. El lobo, al escuchar esto, exclamó: «en esa casa se dicen unas cosas, pero se hacen otras». La fábula concluye indicando que eso podría aplicarse a aquellas personas que

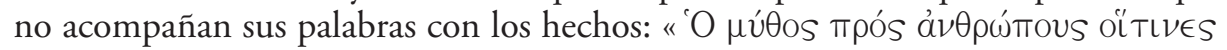
Tá ép

El epimitio en el texto de Esopo es mucho más general que los versos que se encuentran en Babrio y en Avianus ya que declara simplemente que las palabras de los hombres no concuerdan con sus actos. Por otra parte, la narración comienza con la aparición del lobo y se cierra con la reflexión del animal en estilo directo: «Ẻ $\tau \hat{~}$ protagonista es desempeñado por lobo, pero su comportamiento depende directa- 
mente de las palabras que la vieja en estilo directo le dirige al niño en dos ocasiones. Al mismo tiempo parece conveniente destacar que, mientras en la primera alocución

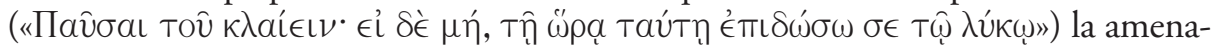

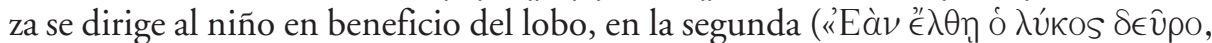

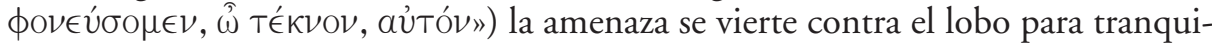
lidad del niño. Esta contraposición permite advertir en Esopo la censura contra la falsedad del ser humano, mientras que en Babrio y en Aviano esta crítica se restringe en sus epimitios al género femenino.

Babrio, por su parte, interviene para modificar la fábula tanto en el contenido como en la forma. De un lado, comienza la narración relatando lo que acontecía a una nodriza que, ante los llantos incesantes de un niño, lo amenazaba, y reproduce

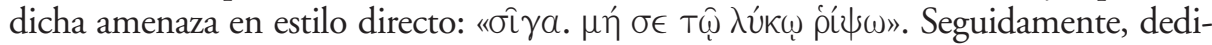
ca cinco versos a la descripción de la aparición del lobo y de su proceder. De otro lado, introduce la figura de la loba que vive con el animal y que le recrimina el hecho de que regrese a casa sin traer nada, palabras que también figuran en estilo directo, dando así pie al epimitio. De hecho, el epimitio de Babrio surge de la breve contestación del lobo a la loba cuando esta, extrañada de que vuelva hambriento, le pregun-

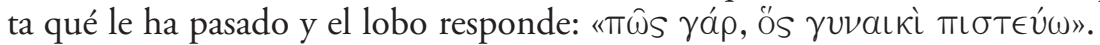

El fabulista, en lo que concierne a los personajes, concede el papel protagonista a los personajes femeninos de la historia, mientras que el lobo es presentado desde una óptica pasiva, quedando su actividad reducida a la espera y a la resignación. En cualquier caso, es la espera la que se enfatiza y se alarga hasta que el sueño se apodera del niño. Además, se elimina la segunda intervención de la nodriza para introducir la de la loba de manera que el lobo queda en medio de dos personajes femeninos. En opinión de Solimano, el lobo «diventa un povero diabolo che debe vedersela con due donne: una che promette, l'altra che rinfaccia» (2005: 347).

Desde el punto de vista de la forma, Babrio eligiendo el coliambo o escazonte, metro propio de la invectiva, para dar forma a sus fábulas, imprime su sello a estos versos que dotan de ritmo a la historia. Como señala Fernández-Delgado (2014: 83), "conocida esta variedad del trímetro ya desde el yambógrafo Hiponacte, la importante revitalización experimentada por el género yámbico en la época helenística propició la reutilización del coliambo como vehículo ya sea de poesía cómica en los llamados mimiambos de Herodas, ya sea de contenidos fabulísticos en los coliambos y meliambos de los poetas cínicos». De esta forma, al igual que los mimiambos, como Estobeo denominó a estos mimos escritos en coliambos, Babrio ofrece, como indica en el prólogo a su segundo libro (Prol. II, vv. 8, 13), sus mythiamboi, transformando así las fábulas mediante la adopción del metro yámbico. En este sentido, del mismo modo que Herondas reinventó el género coliámbico dramáticamente, al mezclar los coliambos con el mimo (López Cruces, 2008: 121), Babrio lo reformó míticamente, al hacerlo con el $\mu \hat{v} \theta o s$, contrapartida del mito. En todo caso, como recuerda Luzzatto (1985: 108), ya Calímaco había empleado el coliambo en la fábula del laurel y el olivo (Iamb. IV), a la que, además, denomina $\mu \hat{v} \theta 0 s$ (Adrados, 1979: 27). En consecuencia, «la "novità" di cui Babrio va cosi orgoglioso non consisteva certo nell'impiego del coliambo per questo genere letterario». Pues, tal y como muestra Perry (1965: LIII-LIV): «The most distinctive feature of the Babrian choliambic line is the never-failing 
selection of a Greek word accented on the penultimate syllable in the last foot. This, as Crusius was the first to point out, is without parallel elsewhere in Greek iambic poetry, but is inevitable in the Roman scazon or choliambic line...».

$\mathrm{Y}$ es que Babrio parece querer resaltar el final anómalo del coliambo con la cantidad y el acento, estableciendo "casi como regla general la cantidad larga de la última sílaba y reforzando la precedente con un acento indefinidamente reiterado" (Brioso, 1972: 123). Brioso lo considera un procedimiento rítmico unitario con el que el fabulista subraya la anomalía del coliambo puesto que en su época esta probablemente dejaría de percibirse con claridad: «En la época de Babrio es comprensible que la singularidad que el coliambo entrañaba en su último pie dejara de percibirse lo suficiente como para impulsar a un poeta cuidadoso a su reforzamiento acentual, es decir, con el medio que tanto la evolución rítmica de la lengua en que se expresaba como el hábito normal del latín ponían a su alcance» (Brioso, 1972: 123-124). Fix, por su parte, destacó la manera en la que Babrio cuidó el final de sus versos de forma que nunca finalizan en monosílabo: «Chez lui en effet, la voix se repose et s'étend, pour ainsi dire, presque toujour sur des syllabes longues de nature, et toujour ces syllabes sont renfermées dans le même mot» (1845: 62).

Así se observa en la composición que nos ocupa en la que quedan resaltados los términos finales de los versos como por ejemplo $\tau i \tau \theta \eta$ en lugar de $\tau \rho \circ \phi o ́ s$, propio de un registro culto (Molinos, 2001: 300), o los verbos ṕi $\psi \omega \omega, \alpha \dot{\lambda} \eta \theta \in \dot{\epsilon} \epsilon \iota \nu, \delta \in \iota \pi \nu \eta \dot{\sigma} \sigma \omega \nu$,

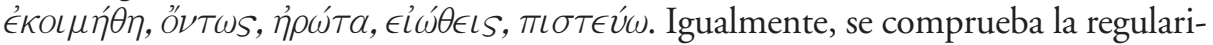
dad de las cesuras de manera que, salvo en el primer verso donde únicamente hay heptemímera, siempre se halla la pentemímera.

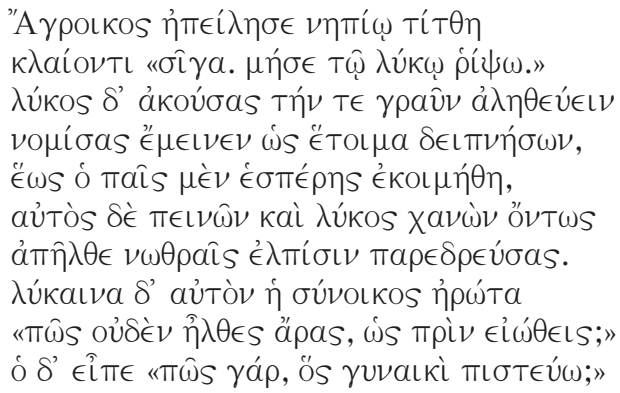

Babrio con una impronta misógina restringe a la mujer, como se ha dicho, el sentido general de la fábula de Esopo que trata del tema de cómo el ser humano hace lo contrario de lo que predica.

La difusión de esta fábula se constata por su aparición junto a otras dos, 11 y 17, también de Babrio en un papiro que contiene adaptaciones de las fábulas para uso escolar, P.Amh., II, 26. Tanto la claridad de su estilo y el metro como la psicología de la que dota a sus personajes, sobre todo a los animales, justifican su presencia en las escuelas (Legran, 1996: 56; Scappaticcio, 2007: 68). Las tres fábulas por sus características paleográficas pueden fecharse en el siglo III o IV. Indica Legran que se utilizarían en las escuelas griegas de Egipto para tratar diversos temas, como instrumento para explicar y legitimar la sociedad existente. 
Este es el caso de la fábula 16 de Babrio en la que se muestra las desigualdades entre hombres y mujeres, y entre los seres humanos y los animales. Comenta Legran que el estudiante escribe esta fábula en traducción latina y en el original griego. En su opinión, esta composición es doblemente misógina por el retrato tanto de la campesina como de la loba, a lo que se añade la estupidez del lobo que cree que la nodriza puede realmente arrojarle el niño en lo que ve, además, tintes misántropos (1996: 76-77). Del mismo parecer es Scappaticcio para quien la misoginia es evidente no solo en el comportamiento de la nodriza sino también de la loba, «avida della preda del suo coniuge». Por otra parte, el retrato que se ofrece del lobo cuya ingenuidad le lleva a confiar en la palabra de la vieja y a sacrificar su tiempo con una vana ilusión, según Scappaticcio, permite conjugar, como ya afirmaba Legran, misoginia con misantropía o, al menos, colegir que se denuncia a aquel que, sin atender a su propia estupidez, está dispuesto a apuntar su dedo contra otro (Scappaticcio, 2017: 102).

En esta fábula, según creo, se entrecruzan dos conceptos. Por un lado, la esperanza, vinculada al personaje masculino y animal que considera por las palabras de la nodriza que puede lograr lo que desea puesto que tiene confianza, concepto asociado negativamente al personaje femenino y humano; por otro, la estupidez, representada igualmente por el animal. A este respecto, considero que no se ha atendido suficientemente a la ironía con la que Babrio describe estos personajes y al tono cómico que cierra la composición. No debe descartarse que Babrio ponga de manifiesto la ridícula actitud de quien espera que una nodriza haga daño a un niño y, en consecuencia, podría atisbarse una burla irónica, cercana a la actitud de los cínicos, quienes sirviéndose de la broma ofrecen sus enseñanzas.

\section{AFTONIO}

Aftonio presenta la misma temática en su fábula 39:

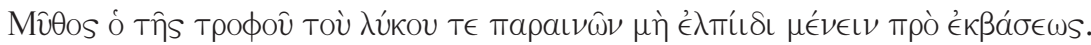

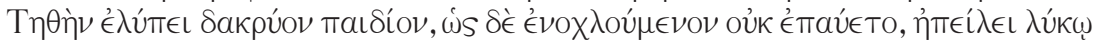

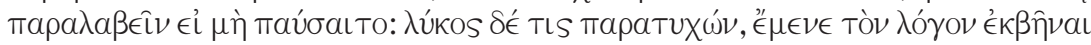

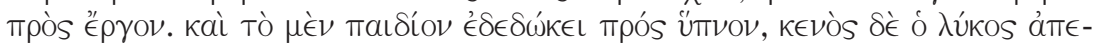

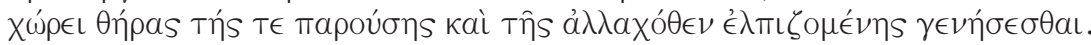

La composición se caracteriza por su brevedad y consta de un epimitio, también de naturaleza didáctica: «"A en el que se aconseja que no se confíe en las promesas del ser humano pero que, en ningún caso, posee tintes misóginos. Es más, el epimitio se centra en la esperanza vana ("A

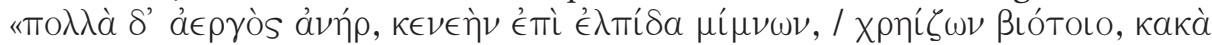

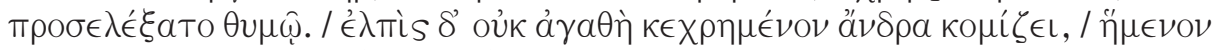

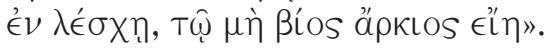

El concepto de esperanza ( $(\dot{\epsilon} \lambda$ mis) en Hesíodo parece tener un sentido connotado negativamente, pues lleva al ser humano a depender de elementos ajenos a él. 
En este aspecto, resulta posible establecer un paralelismo entre esta visión de la esperanza de Hesíodo, profundamente ligada a la necesidad de esfuerzo y trabajo para el ser humano, y la crítica a este lobo que espera recibir su sustento sin esfuerzo y que acaba viendo cómo su esperanza se desvanece. Y es que la vana esperanza es propia del holgazán.

\section{ANÁLISIS COMPARADO}

El análisis comparado de las composiciones permite establecer dos grupos claramente diferenciados no solo por la oposición prosa-verso sino también porque la correspondencia entre las fábulas de cada grupo es mayor desde el punto de vista del contenido. Las similitudes entre Esopo y Aftonio son claras ya que en ellas no aparece el personaje de la loba y se incide por una parte, en la inutilidad de albergar vanas esperanzas y, por otra, en la falta de palabra del ser humano. Sin embargo, debe señalarse que, aunque Aftonio simplifica y abrevia notablemente la historia, coincide con Babrio en la introducción del sueño como elemento temporal que da cuenta de la capacidad de espera del lobo, al igual que hará Aviano, quien también mantiene el personaje de la loba. Ambos, conscientes de la importancia de las estructuras métricas y rítmicas para la fijación de los versos en la memoria, ofrecen sus composiciones en verso, localizan la falta de palabra en el género femenino y con fina ironía acentúan la estupidez del lobo, capaz de creer las hipotéticas amenazas de la nodriza.

\section{AVIANO EN LA EDAD MEDIA}

La reelaboración de las fábulas de Aviano (siglo IV d. C), atendiendo bien a la abbreviatio o a la amplificatio (Chaparro, 2005: 50), fue frecuente tanto en prosa como en verso en los siglos XI a XIV. La popularidad de las fábulas de Aviano en la Edad media fue enorme, circunstancia que se vio favorecida, sin duda, por el metro en que están escritas, el dístico elegíaco. Téngase en cuenta que estas fábulas constituyen una versión elegiaca de las coliámbicas de Babrio. Pero Aviano, en lugar del coliambo, también denominado escazonte o "cojo» elige versos de desigual medida, esto es, el dístico elegíaco, el famoso metro «cojo», pues su ritmo, como describe Alcina «tiene un movimiento recurrente como de volver a empezar que produce la primera mitad del pentámetro, que parece que va a seguir como si fuera otro hexámetro, pero queda suspendido por la cesura y vuelve a comenzar otra vez como si fuera otro hexámetro en la segunda parte. Es una sensación como de metro cojo o de las olas en la playa, ...» (2008: 39). Asimismo, este metro se ajusta a los intereses didácticos que subyacen a las composiciones y a la expresión sentenciosa de la enseñanza que ha de extraerse. De un lado, la facilidad del metro que, además permite el reempleo de expresiones propias de Ovidio y Virgilio (Gaide, 1991: 51), de otro, el deseo de conferir al género de la fábula un estilo más elevado (Bissanti, 2010: 11), esto es, mayor calidad literaria, como indicó Adrados, quién considera que para ello «se apoyó en la existencia de fábulas en dísticos elegiacos en epigramas griegos y latinos» (Adrados, 1991: 41), motivaron la elección del dístico elegiaco. A ello, se suma el 
hecho de que esta estructura métrico-rítmica, como instrumento mnemotécnico, favorecería en gran medida los procesos de aprendizaje.

La difusión de Aviano, como se ha dicho, fue enorme. Además de las diversas adaptaciones y reelaboraciones, cuenta con una colección de epimythia apócrifos y una paráfrasis en prosa, conservada en dos manuscritos del siglo XIV, editada primero por Froehner (1862: 67-84) y más tarde por Hervieux (1894: 353-370).

La composición que nos ocupa, al igual que la demás, constituye una traducción en prosa que no merece mayor comentario, pero en la que el traductor encaja, como puso de manifiesto Hervieux (1894: 172), el epimitio, auténtico o apócrifo, sin variación alguna, apropiándose incluso, como es el caso de esta fábula, de algunos otros versos:

Ne mireris, ait, deceptum fraude maligna

Vix miserum vacua delituisse fuga.

Namque rogas predam. Que spes contingere possit,

Jurgia nutricis cum mihi verba darent?

Hec sibi dicta putet seque hac sciat ar[t]e iocari

Femineam quisquis credidit esse fidem.

(Apologi Aviani, Hervieux, 1894: 353-370).

Asimismo, existe otra paráfrasis de fábulas en prosa, conocida como Anonymi Avianicae fabulae, editada por Hervieux (1894: 319-352). En esta recolección las fábulas acaban con una explicación de su enseñanza moral como en el caso de la fábula que nos ocupa donde dicha enseñanza se encuentra íntimamente relacionada con el epimitio: «Moralitas. Hoc exemplum docemur ne temere credimus verbis mulieris, in quibus, si vana spes intelligi poterit, sive tamen fallacia sive decepcio est annexa» (Hervieux, 1894: 320).

Entre las reelaboraciones o adaptaciones latinas medievales de las fábulas de Aviano en verso se encuentra una colección, atribuida a una poeta de Asti, el Nouus Auianus, probablemente de comienzos del siglo XII, quien somete a una profunda amplificatio las fábulas de Aviano. No obstante, en opinión de Hervieux (1894: 186) su paráfrasis resulta defectuosa tanto en la forma como en el contenido. La fábula, objeto de análisis, aparece entre las composiciones del Astensis poeta, concretamente formando parte del libro III, dedicado, como indica Chaparro (2005: 50), a advertir de los peligros de la credulidad. Desde el punto de vista de la forma, el poeta se esfuerza en rimar, tan ricamente como le es posible, los dos hemistiquios de cada verso en dísticos generalmente leoninos (Hervieux, 1894: 186).

Frente a los ocho dísticos de Aviano, el poeta de Asti ofrece 13 dísticos, el primero constituye un exordio": «Auxilio Phoebi iam carmina multa peregi, / quae

${ }^{2}$ Sobre la posible interpretación de estos versos, vid. Zurli (1994: 33). 
sunt digna foro Maeonidumque choro» y finaliza con un dístico en el que presenta un epimitio de naturaleza misógina en el que se critica el carácter engañoso de las palabras de las mujeres: «Iamdudum legi: non debet femina credi, / cum soleat laedi, qui male credit ei» (Zurli \& Bisanti, 1944: 144).

Por otra parte, en el Antiavianus, nomenclatura ${ }^{3}$ que figura en el manuscrito Dd. XI. 78 del siglo XIII de la Biblioteca de la Universidad de Cambridge, se encuentran la reelaboración de nueve fábulas de Aviano, también en dísticos elegiacos, siendo la primera de ellas De rustica et lupo en cuyos dísticos finales la misoginia está presente tanto en las palabras del lobo como en el epimitio final:

\author{
Hic redit illusus: lupa conjux, "quis tibi," dixit, \\ "Defectus praedae? quae tibi causa famis?" \\ Cui lupus, "illusit fallax me faemina jurans \\ Viscera visceribus pascere nostra suis." \\ Qui falli meruit, exemplo discat in isto \\ Faemineae fidei non adhibere fidem (Tamanza, 1998: 142).
}

Su autor, probablemente de finales del siglo XII o principios del XIII, como señala Bertini (2008: 8), conoce y utiliza las reelaboraciones del poeta Astensis y del Avianus Vindobonensis.

En el Novus Avianus de Darmstadt se encuentran en hexámetros leoninos las fábulas de Aviano y la primera de ellas finaliza con el siguiente epimitio: «Femineo more cor sepe recedit ab ore; / Lingua quod ostendit verbis, animus reprehendit» (Vernetti, 2004: 268).

Como puede comprobarse, el Avianus de Darmstadt se aleja de las sentencias que centran su atención en la desconfianza sobre el género femenino y en la línea de Esopo, aunque referido únicamente a las mujeres, incide en que las palabras no se corresponden con los sentimientos.

El texto del Avianus Vindobonensis contiene cuarenta fábulas en dísticos elegiacos leoninos. La obra probablemente de finales del siglo XII o comienzos del XIII (Hervieux, 1894: 207) presenta un epimitio para la fábula I también de naturaleza misógina: «Hec ratio prebet vix credi femina debet; / sepe fit ut doleat credere qui soleat». Este epimitio, como puede verse, presenta ciertas concomitancias con el del poeta de Asti: «lamdudum legi: non debet femina credi, / cum soleat laedi, qui male credit ei». Ambos autores resumen en un único verso lo expresado por el dístico final de Aviano: «Haec sibi dicta putet seque hac sciat arte notari / femineam quisquis credidit esse fidem" (Gaide, 1980: 79). Del mismo modo, muestran gran paralelismo en el pentámetro de nueva creación: sepe fit ut doleat credere qui soleat (Vindob.) / cum soleat laedi, qui male credit ei (Asti).

${ }^{3}$ Aparece en este manuscrito la inscriptio «Incipit Antavanus», corrupción de «Anti-Avianus» (Hervieux, 1894: 262). 
Todo ello y otras razones expuestas por Hervieux (1894: 218-220) ponen de manifiesto que mientras el Poeta de Asti reelaboraba mediante una imitación directa la obra de Aviano, el autor del Anonimus Vindobonensis seguía de cerca al Astensis poeta.

El Novus Avianus de Neckam de finales del siglo XII ofrece también un Novus Avianus, pero limitándose a la adaptación de las seis primeras fábulas de Aviano. La primera de ellas presenta un epimitio en el que, apartándose de las lecturas misóginas, el autor subraya el carácter engañoso de la esperanza y desaconseja la confianza en las promesas: «Spes fallax multos fallit, sors lubrica ludit; / promissis non est semper habenda fides». (Klein, 1998: 114-116; Hervieux, 1894: 462-463). Por otro lado, como puso de manifiesto Bissanti (2010: 130), aquí se suprime el retorno del lobo a la cueva y la aparición del personaje de la loba, circunstancia que, desde mi punto de vista, es absolutamente natural puesto que se halla en la línea de las composiciones de Esopo y Aftonio en las que no aparece el personaje de la loba y se incide de un lado, en la inutilidad de albergar vanas esperanzas y, de otro, en la falta de palabra del ser humano.

El Novus Avianus de Venecia (S. XIII), reelaboración del texto avianeo también en dísticos elegiacos, presenta grandes concomitancias con otras reelaboraciones, especialmente con la del poeta de Asti.

Con objeto de garantizar la coherencia narrativa interna el autor del Novus Avianus de Venecia, como ha indicado Mordeglia (2012a: 365), en el último dístico del prólogo procede a presentar la primera fábula: «Ne tamquam veris verbis credas mulieris, / disce lupi monitis principio positis» (Mordeglia, 2004: 54). Este dístico se halla en perfecta harmonía con el perfil misógino de esta composición en cuyo epimitio denuncia la falta de palabra y la inconstancia de las mujeres: «Nemo putet verum iuramentum mulierum / exquando quidem non habet ulla fidem» (Mordeglia, 2004: 58).

Por último, atenderé a los resúmenes de las fábulas de Aviano que fueron frecuentes en la Edad Media. Como indicó Hervieux (1894: 242), en la Biblioteca Imperial de Viena se encuentra un manuscrito en el que se conservan dos resúmenes, uno a continuación del otro. En el primero las cuarenta y dos fábulas aparecen reducidas a cuartetos en los que los cuatro versos riman entre ellos con una sola rima disilábica, si bien algunas presentan dos cuartetos y tres la fábula treinta y cinco. Se trata de versos rítmicos de trece sílabas, divididos en dos hemistiquios de siete más seis sílabas con acento en la antepenúltima sílaba del primer hemistiquio y en la penúltima del segundo.

Desde el punto de vista del contenido, los cuatro versos tienen más que ver con los epimithya que con la fábula, pero se hallan, como apunta Hervieux (1894: 242), en perfecta harmonía con la fábula en cuestión.

De la fábula I esta es la moralización rítmica:

Vt nullus faciliter prave mulieri

Credat, per hanc fabulam poterit haberi;

Nam, sicut audivimus lupus inde queri,

Sic potest vir quilibet simile vereri (Hervieux, 1894: 480). 
El segundo resumen presenta también cuartetos que al igual que el anterior solo atienden a la moraleja que se desprende de cada fábula pero ahora en dísticos elegiacos leoninos (Hervieux, 1894: 245).

En el caso de la fábula que nos ocupa, esta es la moralización métrica:

Rustica dum iurat flenti, Lupus est prope; durat,

Credens quod sit ibi preda parata sibi.

Nil datur: ecce doli speciem. - Rogo, figere noli

In muliere fidem, ne paciaris idem (Hervieux, 1894: 491).

Estas «moralizaciones», ejercicios escolares de los siglos XIII y XIV, ponen de manifiesto la interpretación misógina de esta fábulas, pues en ambas se aconseja no fiarse de las mujeres para no sufrir las mismas consecuencias que el lobo.

Por otra parte, como ha puesto de manifiesto Mordeglia (2012a), debido a la enorme difusión de Fedro y Aviano durante la Edad Media a través de la praxis didáctica y el folclore, existe una importante relación entre la Disciplina Clericalis de Petrus Alfonsi y la fábula latina.

En el ejemplo de la Disciplina Clericalis «De aratore et lupo iudicioque vulpi» ${ }^{4}$ se constatan paralelismos con la fábula que estamos analizando puesto que versa sobre la conveniencia de no fiarse de la palabra de otro. Igualmente, tiene lugar una amenaza, en esta ocasión proferida por un labrador a unos bueyes a los que les dice que los lobos se los van a comer por no querer hacer un surco. Del mismo modo, un lobo que escucha dicha amenaza, espera inútilmente y finalmente reclama al labrador que cumpla su promesa: Dictum namque fuit de uno aratore quod boves illius recto tramite nollent incedere. Quibus dixit: Lupi vos comedant! Quod lupus audiens adquievit. Cum autem dies declinaretur et iam rusticus ab aratro boves solvisset, venit ad eum lupus ita dicens: Da mihi boves quos mihi promisisti!...

\section{PERVIVENCIA DE ESTA FÁBULA}

Por último, parece adecuando establecer alguna relación entre esta fábula y la canción de cuna. De hecho, en el mundo clásico las nodrizas y nanas ya cantaban a los niños cancioncillas para que se durmiesen y en ellas era usual que se les amenazase con llamar al lobo u otros personajes, reales o imaginarios, capaces de dar miedo. Esta fábula muestra claras concomitancias con varias nanas, propia de la tradición hispana, que forman parte del imaginario simbólico, así esta canción

${ }^{4}$ Las concomitancias de este ejemplo de la Disciplina Clericalis y la fábula que nos ocupa han sido señaladas por distintos estudiosos (Jacobs, 1889: 258; Talavera Cuesta, 2007: 325; Mordeglia, 2012: 362-363). 
de cuna en versos hexasílabos, "Duérmete, niño, / duérmete ya, / que viene el lobo / y te comerâ" o en versos octosílabos: "A dormir, que viene el lobo / y si no, viene la loba / preguntando de casa en casa / cuál es el niño que llora” (Cerrillo, 1992, nº. 2).

\section{CONCLUSIONES}

Tal y como ha podido comprobarse, una buena parte de las reelaboraciones de esta fábula presentan como tema común la consideración de que las mujeres son incapaces de mantener su palabra, circunstancia que aconseja no confiar en ellas. El epimitio de la fábula de Aviano advierte de que no es aconsejable fiarse de las mujeres $y$, en este sentido, contribuye al establecimiento de una imagen prefijada del sexo femenino y a la formación de un arquetipo de mujer engañosa. En la misma línea se encuentra Babrio al circunscribir a la mujer con una evidente impronta misógina el sentido general de la fábula de Esopo que trata acerca de cómo el ser humano hace lo contrario de lo que predica. En cualquier caso, creo que debe atenderse también a la burla irónica de la que se sirve Babrio al describir la estúpida figura del confiado lobo, aspecto que también queda de manifiesto en la composición de Aftonio, ajena a cualquier propósito misógino, cuyo epimitio se centra en la crítica de la esperanza vana, propia del perezoso.

Las reelaboraciones de esta fábula en la Edad Media, en general, muestran enseñanzas morales de naturaleza misógina, así las paráfrasis en prosa, denominadas Apologi Aviani y Anonymi Avianicae fabulae. De igual forma, las versiones en verso que, a excepción del autor de Avianus de Darmstadt, quien incide en que las palabras de las mujeres no se corresponden con sus sentimientos, y del autor del Novus Avianus de Neckam, quien, apartándose de las lecturas misóginas, subraya el carácter engañoso de la esperanza y desaconseja la confianza en las promesas, ofrecen un claro perfil misógino, denunciando la falta de palabra y la inconstancia de las mujeres. La misma interpretación misógina muestran las moralizaciones rítmica y métrica.

Por otra parte, como se ha visto, aunque el ejemplo de la Disciplina Clericalis «De aratore et lupo iudicioque vulpi» presenta paralelismos con esta fábula, carece de tono misógino alguno. Ajenas a este tipo de interpretaciones se hallan también algunas nanas que parecen reproducir las amenazas que profiere la nodriza al niño para que se duerma. Son estas canciones en las que ni cabe duda alguna acerca de las intenciones de quien pronuncia tales amenazas, ni se halla mención alguna al hecho de que el lobo de la fábula las creyese a pies juntillas. De lo que sí hay certeza es de la difusión de esta fábula y de su adaptabilidad. Y es que, como señala Mordeglia (2012: 356), «la versatilità della morale, adattabile a vari contesti ideologico-culturali, è stata proprio il principale garante della loro fortuna nel tempo».

\section{REFERENCIAS BIBLIOGRÁFICAS}

Alcina, J. F. (2008): «La elegía neolatina», en B. López Bueno (ed.), La poesía del Siglo de Oro. Géneros y Modelos, Sevilla: Universidad de Sevilla, pp. 15-40. 
Bádenas de la Peña, P. y López Facal, J. (2004): Fábulas de Esopo. Vida de Esopo. Fábulas de Babrio, Madrid: Gredos.

Bertini, F. (2008): «A proposito di alcune raccolte di favolisti medievali», Mediaeval Sophia 4: 5-19.

BisANTI, A. (2010): Le favole di Aviano e la loro fortuna nel Medioevo, Firenze: SISMEL - Edizioni del Galluzzo.

(2014): «Tradizione fedriana e tradizione orientale nela favolistica mediolatina - Status quaestionis», en Caterina Mordeglia (ed.), Lupus in Fabula. Fedro e la favola latina tra Antichità e Medioevo. Studi offerti a Ferruccio Bertini, Bologna: Pàtron, pp. 181-200.

BRIOSO, M. (1972): «Aportaciones al problema de la Métrica griega tardía», Est. Clás. XVI, 65: 95-138.

CAscón Dorado, A. (1986): «Misoginia en Fedro», en E. Garrido GonZÁlez (ed.), La mujer en el mundo antiguo. Actas de las V Jornadas de investigación interdisciplinaria, Madrid: Universidad Autónoma de Madrid, pp. 281-288.

(2005): Fedro, Fábulas. Aviano, Fábulas. Fábulas de Rómulo, Madrid: Gredos.

Cerrillo Torremocha, P. C. (1992): Antología de nanas españolas, Ciudad Real: Perea Ediciones.

ChAPARRo GÓMEz, C. (2005): «La fábula latina: entre ejercicio escolar y pieza literaria», Forma breve 3: 33-54.

CORTÉs TOVAR, R. (2000): «Misoginia y literatura en la tradición greco-romana», en Ma T. LÓPEZ DE LA VIEJA (ed.), Feminismo: del pasado al presente, Salamanca: Universidad de Salamanca, pp. 15-34.

(2007): «La fábula: Fedro», en C. CoDOŃER (ed.) Historia de la literatura latina, Madrid: Cátedra, pp. 395-400.

De MARIA, L. (1987): La femina in Fedro. Emarginazione e privilegio, Lecce: Adriatici Editrice.

ElLIS, R. (1887): The fables of Avianus, Oxford: Clarendon Press [reimpr. Hildesheim, 1966].

FernÁNDEZ-Delgado, J. A. (2014): «Babrio en la escuela grecorromana», en F. Mestre \& P. GÓMEZ (eds.), Three Centuries of Greek Culture under the Roman Empire: Homo Romanus Graeca Oratione, Barcelona: Universidad de Barcelona, pp. 83-100.

FIX, T. (1845): «Babrii Fabulæ iambicæ CXXIII nunc primum editæ. Jo. Fr. Boissonade recens. latine convert. annotav. —Babrii Fabula: iambicæ CXXI Jo. Fr. Boissonade recens. 2a ed. —Animaduersiones criticæ in Babrii Mythiambois. Scr. Fr. Dubnerus. Examen critique», RPh 1: 46-81.

Froehner, G. (1862): Aviani Fabulae, XLII. ad Theodosium, Leipzig: Teubner.

Gaide, F. (1980): Avianus, Fables, Paris: Les Belles Lettres.

_ (1991): «Avianus, ses ambitions, ses résultats», en G. CATANZARO \& F. SANTUCCI (dirs.), La favolistica latina in distici elegiaci. Atti del convegno internazionale (Assisi, 26-28 ottobre 1990), Assisi: Accademia properziana del Subasio, pp. 45-61.

Guaglianone, A. (2000): I favolisti latini, Napoli: Giannini.

Herrmann, L. (1950): Phèdre et ses fables, Leiden: E. J. Brill.

Havet, L. (1895): Phedri Augusti liberti Fabula Asopia, Paris: Hachette.

Hausrath, A. \& Hunger, H. (1970 / 1959): Corpus fabularum Aesopicarum I y II, Leipzig: Teubner.

Hervieux, L. (ed.) (1894): Les Fabulistes Latines depuis le siècle d'Auguste jusqu' à la fin du moyen âge. Vol. 3: Avianus et ses anciens imitateurs, Paris: Firmin-Didot. 
JACOBS, J. (1889): The fables of Aesop, as first printed by William Caxton in 1484, with those of Avian, Alfonso and Poggio, London: D. Nutt.

KLeIn, TH. A.-P. (1998): Alexander Neckam, Novus Avianus, en Favolisti latini medievali e umanistici VII: 99-136, Genova: Università degli studi di Genova, D.Ar.Fi.Cl.Et «F. Della Corte».

LEgras, B. (1996): «Morale et société dans la fable scolaire grecque et latine d'Égypte», CCG 7: 51-80.

LuZZATTO, Ma J. (1985): «Fra poesia e retorica: la clausola del "coliambo" di Babrio», QUCC 19 (1): 97-127.

Mañas NúÑez, M. (ed.) (1998): Fedro y Aviano. Fábulas, Madrid: Akal.

(1999): «Ensayo de crítica literaria y comparada: a propósito de algunas versiones de la fábula

"El grajo soberbio y el pavo" (Phaedr. I 3)», Anuario de Estudios Filológicos XXII: 225-244.

Mordeglia, C. (2012a): «La favola latina e la "Disciplina clericalis" di Pietro Alfonsi», Maia 64 (2): 355-367.

- (2012b): Le favole di Aviano e il «Novus Avianus» di Venezia, Genova: Il Melangolo.

Mordeglia, C. \& Vernetti, E. (ed.) (2004): Il «Novus Avianus» di Venezia. Il «Novus Avianus» di Darmstadt, en Favolisti latini medievali e umanistici XI, Genova: Università degli studi di Genova, D.Ar.Fi.Cl.Et «F. Della Corte».

NøjgaArd, M. (1967): La Fable antique. Tome II, Les Grands Fabulistes, Copenhagen: Nyt Nord Forlag.

Molinos, Ma T. (2001): «Las nodrizas en la escena clásica», en F. De Martino \& C. Morenilla (coord.), El fil d'Ariadna, Bari: Levante Editori, pp. 299-316.

Perry, B. E. (ed.) (1965): Babrius, Phaedrus. Fables, Cambridge, MA: Harvard University Press.

SCAPPATICCIO, Ma C. (2017): Fabellae. Frammenti di favole latine e bilingui latino-greche di tradizione diretta (II-IV d.C.) (Untersuchungen zur antiken Literatur und Geschichte, 128), BerlinBoston: De Gruyter.

Rodríguez Adrados, F. (1979-1987): Historia de la fábula greco-latina, 3 vol., Madrid: Universidad Complutense.

— (1991): «De la fábula griega a la fábula latina en dísticos elegiacos», en G. CATANZARO \& F. SANTUCCI (dirs.), La favolistica latina in distici elegiaci. Atti del convegno internazionale (Assisi, 26-28 ottobre 1990), Assisi: Accademia properziana del Subasio, pp. 4561.

SAlVAdori, E. (ed.) (2005): Il «Novus Avianus» di Vienna, en Favolisti latini medievali e umanistici XII, Genova: Università degli studi di Genova, D.Ar.Fi.Cl.Et «F. Della Corte».

Solimano, G. (2005): Fedro e Aviano, Favole, Torino: UTET.

TAMAnZA, S. (1998): L'Anti-Aviano, en Favolisti latini medievali e umanistici VII: 137-193, Genova: Università degli studi di Genova, D.Ar.Fi.Cl.Et «F. Della Corte».

Zurli, L. (ed.) - Bisanti, A. (trad.) (1994): Astensis Poetae Novus Avianus, en Favolisti Medievali e Umanistici v, Genova: Università degli studi di Genova, D.Ar.Fi.Cl.Et «F. Della Corte». 
